\title{
Effect of Laser Ablation on the Physicochemical Properties of Microwave-Assisted Synthesized AgNP in Aloe Vera (Aloe Barbadensis) Extract
}

\author{
Lamin S. Kassama ${ }^{*}$, Abiola J. Kuponiyi ${ }^{1}$, Tatiana Kukhtareva ${ }^{2}$ \\ ${ }^{1}$ Food Engineering Laboratory, Department of Food and Animal Sciences, A-101 Carver Complex Thomas Wing South, Alabama \\ A\&M University, Normal, AL, USA \\ ${ }^{2}$ Department of Physics, Chemistry \& Mathematics, Alabama A\&M University, Normal, AL, USA
}

Email: ${ }^{\star}$ Lamin.kassama@aamu.edu

How to cite this paper: Kassama, L.S., Kuponiyi, A.J. and Kukhtareva, T. (2017) Effect of Laser Ablation on the Physicochemical Properties of Microwave-Assisted Synthesized AgNP in Aloe Vera (Aloe Barbadensis) Extract. Advances in Chemical Engineering and Science, 7, 393-407.

https://doi.org/10.4236/aces.2017.74028

Received: June 29, 2017

Accepted: September 1, 2017

Published: September 4, 2017

Copyright (C) 2017 by authors and Scientific Research Publishing Inc. This work is licensed under the Creative Commons Attribution International License (CC BY 4.0).

http://creativecommons.org/licenses/by/4.0/

\section{(c) (i) Open Access}

\begin{abstract}
Biosynthesis of silver nanoparticles (AgNP) using biomolecular extracts of plant origin is of interest to many researchers because of their potential to produced stable product. It is hypothesized that laser ablation of the AgNP in solution will enhance the biomolecules such as aliphatic amines, alkenes $(=C-H)$, alkanes $(C-H)$, alcohol $(O-H)$ and unsaturatedesters $(C-O)$ in the Nano emulsion. Hence, the objective of this study was to evaluate the effect of laser oblation on the physicochemical properties and stability of AgNP reduced with Aloe vera (Aloe barbadensis). Experiments were conducted with the pre-made AgNP were subjected to the three laser oblation treatments: 1) Control no laser treatment of AgNP, 2) Laser ablation treatment for 5 minutes and 3) Laser ablation treatment for 10 minutes. The results of the analysis show that laser oblation treatment has significant effect $(p<$ $0.01)$ on the concentration of AgNP. The intensity of the absorption peak significantly $(p<0.01)$ increases with laser exposure time. While $214 \mathrm{ppm}$ was observed with no laser treatment, 224 and 229 ppm increase of concentration was observed when laser treated for 5 and $10 \mathrm{~min}$. The rates of reaction of restructuring the particles sizes were $0.384,0.408$ and $0.4288 \mathrm{~min}^{-1}$ at different laser exposure treatments times 0,5 and $10 \mathrm{~min}$, respectively. The FTIR results show significant $(p<0.05)$ increase in biomolecules concentration of aliphatic amines, alkenes $(=C-H)$, alkanes $(C-H)$, alcohol $(O-H)$ and unsaturatedesters $(C-O)$.
\end{abstract}

\section{Keywords}

Laser Ablation, Silver Nanoparticles, Microwave, Aloe Vera, FTIR 


\section{Introduction}

Different physicochemical approaches have been used by researchers to synthesize AgNP, these methods require the use of either strong or weak chemicals as reducing and protecting agents. Sodium citrate, sodium borohydride and alcohols are typical reducing and protecting agents [1]. However, the disadvantages of organic chemical as reducing agents are associated to their: low rate of synthesis, flammability and toxicity and effluent (a primary environment concern) [2] [3] [4] [5]. Hence, there is growing interest on alternate reduction agents benign to the environment, and plant extracts containing biomolecule are worthy and viable alternative reducing agent [6]. Kalishwaralal, Deepak, Ramkumarpandian, Nellaiah and Sangiliyandi [7] have used plant extracts to synthesizedhighly stable AgNP (40 nm), the biomolecular interaction with the silver ions contributed to the stable products. Nair and Pradeep [8] used Lactobacillusstrains with silver ions in the biosynthesis of nanoparticles and they alluded to the fact that if the lactic acid bacteria metabolites in whey protein are mixed with silver ion with results to the nucleation of the silver ions hence formation of AgNP.

Plants are known to chelate metals unlike microorganisms which are sensitive to metal ions. The ability of plant matrix to accumulate higher concentration of metal ions and the presence of biomolecules (polyphenols, flavonoids, etc.) enhance reduction, hence formation of particulates [9]. Bio-molecules provide a better reduction capacity compared to living organisms, hence synthesize a more stable AgNP [10] [11]. Hence, the method is referred as green and eco-friendly synthesis, it is low cost, eases in availability and much safer to handle [12].

Many researchers have synthesis AgNP using medicinal plant extracts [13] [14] [15]. Kasthuri, Kathiravan \& Rajendran [16] used the following medicinal plants (Oryza sativa, Helianthus annus, Saccharumofficinarum, Sorghum bicolour, Zea mays, Basella alba, Aloe vera Capsicum annuum, Magnolia kobus, Medicago sativa (Alfalfa), Ci namomumcamphora and Geranium sp.) extracts for bio-manufacturing of AgNP. Aloe vera plant is a shrubby, perennial, xerophytic, succulent, pea-green colored medicinal plant with fibrous or woody short stems covered by dense leaves partially buried in the soil. Aloe vera is a good candidate for the synthesis of nanoparticles because it contains functional bio-molecules (fat soluble photochemical such as flavonoids, organic acids and quinines). These chemical compounds found in Aloe vera are associated to the prevention of chronic and degenerative diseases [17]. They are known to neutralize reactive oxygen species by reducing the $\mathrm{Ag}^{+}$ion to $\mathrm{Ag}^{0}$ during the synthesis of $\mathrm{AgNP}$ [18] [19].

The rapid heating and penetration of microwave energy provide a significant advantage, because of the instantaneous and uniform energy distribution over the volume of the reaction, hence, shorten the chemical reaction period while the particle size distribution is enhanced [20]. Microwave heating is not new in the food industry and has various applications in the synthesis of different mate- 
rials (benzyl chloride to benzyl alcohol, 1, 3-Dipolar cycloadditions of organic azides to ester or benzotriazolylcarbonyl activated acetylenic amides) [20]. Laser ablation is a process of optical amplification based on the stimulated emission of electromagnetic irradiation resulting to localized heating and photoionization [21]. Bauer, Abid, Ferman \& Giault [22] used the laser oblation mechanism to excite AgNP in solution with ultrafast (femtosecond Picosecond and nanosecond) beam, which generates instantaneous relaxation of the hotelectrons, hence the Localized Surface Plasmon Resonance (LSPR) band resulted in the melting and eventual reduction of the targeted metal particles. It is therefore, hypothesized that laser ablation of the AgNP in solution will enhance the biomolecules such as aliphatic amines, alkenes $(=C-H)$, alkanes $(C-H)$, alcohol $(O-H)$ and unsaturatedesters $(C-O)$ in the Nano emulsion.

Fourier Transform Infrared (FTIR) has been used to determine concentration of bioactive compounds in plants extracts used as reducing agents of AgNP [23]. This technique has also been used by various researchers in the characterization of AgNP and AuNP and their associated biomolecules from plant extracts [4] [24] [25]. Hence, the objective of this study was to evaluate the effect of laser ablation on the physicochemical properties and stability of AgNP reduced with Aloe Vera (Aloe barbadensis).

\section{Materials and Methods}

\subsection{Sample Preparation}

The Aloe vera leaves were collected from the Alabama A\&M University greenhouse in August, 2015 and were sterilized with ethanol to remove traces of soil, dirt and other debris. The parenchymatous (skin) of the leaves were separated from the gel by using an ethanol-sterilized surgical blade. The samples were ground with a coffee grinder to increase the surface area. Ten (10) grams of the ground Aloe vera skin material was placed in a $250 \mathrm{~mL}$ of Erlenmeyer flask and $50 \mathrm{~mL}$ ethanol was subsequently added and the extraction proceed overnight. The raffinate was filtered with a Whatman filterpaper (4 - $8 \mathrm{um}$ ).

The filtered Aloe Vera extract $3 \mathrm{~mL}$ was combined with 0.011 grams of silver nitrate and synthesized using a Microwave Work Station-240 with FISO Commander Workstation software for sensors and result management (FISO Technologies Inc. Quebec, Canada) and the $\mathrm{pH}$ of the Nanosolution was adjusted to 10 prior to the synthesis and was microwaved for $15 \mathrm{~min}$. All the synthesis was conducted in a dark room to avoid $\mathrm{Ag}$ from absorbing light.

\subsection{Laser Illumination Treatments}

The particle size distribution was modified by exposing the Nanosolutions to the Nanosecond Pulse Laser (Surelite SL1-10 Seymour, CT, USA, $\lambda=1064 \mathrm{~nm}, \mathrm{P}=$ $450 \mathrm{~mL}, 532 \mathrm{~nm}, \mathrm{P}=200 \mathrm{~mJ}$ ) illumination treatments for 5 and $10 \mathrm{~min}$. The laser illumination of $2 \mathrm{~mL}$ aliquots of aqueous colloidal solutions contained in a quartz cuvette (optical path length $1.0 \mathrm{~cm}$, width $1.0 \mathrm{~cm}$, height $2.0 \mathrm{~cm}$ ) were 
conducted using the second and third harmonics setting of the laser according to the method described by Werner \& Hashimoto [26]. Samples were collected and stored in the Food Engineering Laboratory walking refrigerator until needed for analysis.

\subsection{Surface Plasmon Resonance UV-Visible Spectrophotometer}

The absorption spectra of the AgNP on solutions were characterized with a UV-Visible spectroscopic (Cary 3E UV-Vis, Varian PTY Ltd. Australia). The samples (AgNP synthesized in solution) $2 \mathrm{~mL}$ were placed in a quartz cuvette which was subsequently subjected to the UV spectroscopy to measure the absorption of colloidal suspension (hydrosol) and detection of the surface Plasmon resonance absorption peak.

\subsection{Particle Size Distribution and Stability Measurements}

Dynamic Light Scattering technique was used to analyze and quantify the particle size distribution of the AgNP. The Zetasizer Nano Series (ZEN 3690, Malvern Instruments Ltd, Worcestershire, UK) is the premium system in the Zetasizer range. AgNP synthesized were centrifuged to remove excess liquid prior performing the particle size and stability test. Three milliliter of the AgNP synthesized was placed in a quartz cuvette, and measurements were taken by intensity and volume according to the method developed by Kassama et al. [13]. The electrokinetic potentials (Zeta potential) of AgNP was also measured to determine the stability of the AgNP.

\subsection{FTIR Spectra Determination of Functional Groups}

About 0.0016 grams of the treated samples were dropped on the FTIR card (Real Crystal IR Card, $-9.5 \mathrm{~mm}$ Aperture, International Crystal Labs, New Jersey, USA) according to the method described by Chandran et al. [25] and allowed to dry. The cards were placed in the card slot section and the infrared light passed through, and continuing wave captured by the detector connected to a microcomputer (Thermo Fisher Scientific Smart Omni transmission, Madison, WI) hence displays the spectral profile corresponding to the different functional groups in the samples.

\subsection{Experimental Design and Statistical Analysis}

The experimental was a two-factor factorial design consisting of: Factor 1) Laser illumination with 3 levels of exposure time $\left(0 \mathrm{~min}=\mathrm{T}_{82}, 5 \mathrm{~min}=\mathrm{T}_{83}\right.$, and $10 \mathrm{~min}=$ $\mathrm{T}_{84}$ ); and Factor 2) Storage time with 3 levels of time (1, $3 \& 6$ weeks). The experimental data obtained was analyzed using SAS software (SAS v.8, Nashville). Mean comparison by Duncan's multiple range test (DMRT) was used to separate treatment means (5\% level of significance) for treatments that were significant by the Analysis of Variance (ANOVA). All experiments were carried out in triplicates and statistical tests were performed at $5 \%$ level of significance. 


\section{Results and Discussions}

\subsection{Laser Ablation Surface Plasmon Resonance}

The AgNP nanosolutions were exposed to laser treatment for 0, 5, 10 min and stored for six weeks to evaluate its structural integrity and stability. The effect of laser treatment on the Surface Plasmon Resonance (SPR) spectral profile was monitored for each treatment and shown in Figure 1. The spectral characteristic absorption peaks at around $400 \mathrm{~nm}$ correspond to a surface plasmon band reported by Bae et al. [27] for AgNP. A surface plasmon peak shift to a slightly longer wavelength at a new peak of $430 \mathrm{~nm}$ was observed in Figure 1. The slight variation of the results could be attributed to the laser treatment, however the formation of AgNP at $430 \mathrm{~nm}$ is in line with values reported by Kassama et al. [13] [28]. The analysis of variances (ANOVA) of the results indicated that exposing AgNP solution to laser treatment significantly $(p<0.001)$ increase the concentration of nanoparticles. The intensity of the absorption peak was observed to increase significantly $(p<0.01)$ by $7 \%$ with 10 min laser exposure (Figure 1), similar observations was reported by Werner \& Hashimoto [26].

The surface plasmon peak shift which appears at the low-energy region could have influenced the $7 \%$ increase in nanoparticle concentration, because of the isolated particles that form densely packed aggregates through dipole interaction between the neighboring particles. Interestingly, this has manifested by the color variation of the nanosolutions during the laser oblation treatments. Moreover, the color intensity is due to the optical properties of AgNP which is strongly dependent on the particle size and shape. The optical properties were dominated by the collective oscillation of the conducting electrons resulting from the interaction with electromagnetic radiation during laser oblation [29].

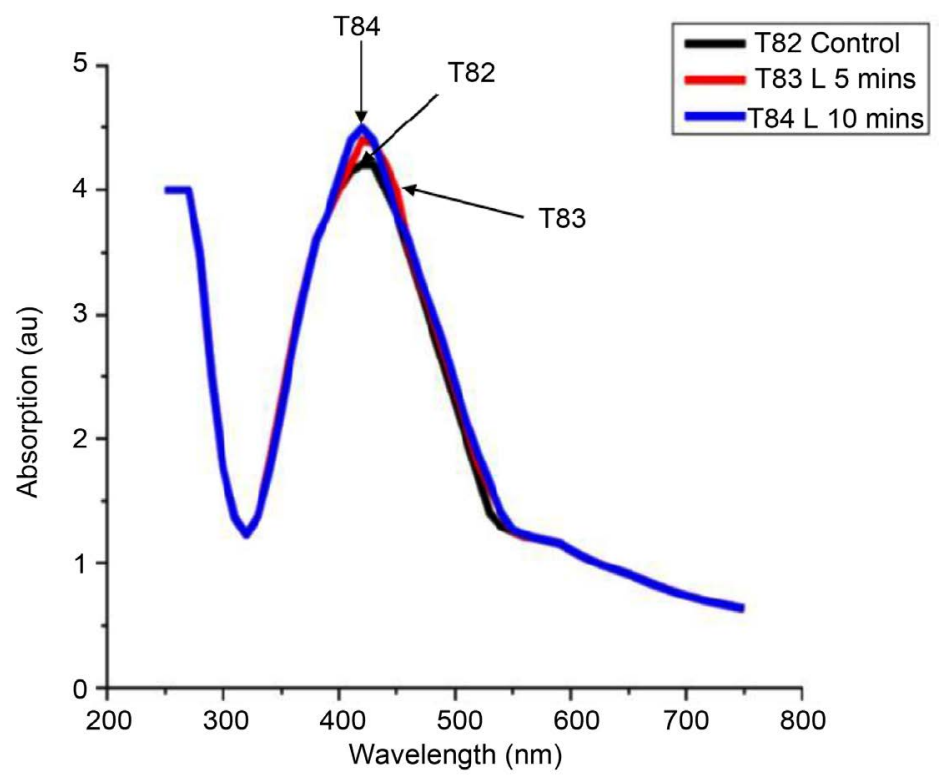

Figure 1. Surface Plasmon resonance spectral profile of AgNP solution exposed to laser oblation treatments at time 0 (T82), $5 \mathrm{~min}$ (T83), and 10 $\min (\mathrm{T} 84)$. 
It was observed that the concentration and absorption increase with laser exposure time, thus the control (no treatment) had a concentration of $214 \mathrm{ppm}$ while laser exposures for $5 \mathrm{~min}$ and $10 \mathrm{~min}$ produced a higher concentration of 224 and 229 ppm, respectively (Table 1). However, no significant change in concentration $(p>0.05)$ was observed during the six-week-storage period and no synergy $(p>0.05)$ was observed between the laser oblation and storage time. This is a unique physical attribute that denotes storage stability of laser treated AgNP.

\subsection{Kinetics of Reaction}

The rate of reaction as a result of laser regeneration of the synthesis AgNP in solution is a zero-order reaction. Hence, a direct proportionality between AgNP concentrations and reaction time is shown in Figures 2(a)-(c). Although, few researchers reported the order of reaction in the biosynthesis of AgNP in the literature, yet Nair \& Panda [30] reported the same order of reaction using Fusarium oxisporum to synthesize AgNP. The rate constants were calculated using the rate law, whereby the rate of disappearance of reactant is proportional to the concentrations of product formed. The rate constants for the different treatment exposure times, $0 \mathrm{~min}$ (no laser), $5 \mathrm{~min}$ and $10 \mathrm{~min}$ were $0.384,0.408$ and 0.4288 $\min ^{-1}$, respectively.

\subsection{Particle Size Distribution and Stability Measurements}

The results of the ANOVA showed that laser oblation significantly $(p<0.01)$ reduces particles sizes and thus impact the particles size distributions. However, no significant $(p>0.01)$ interactions were observed between laser oblation and storage time. The particle size distributions (PSD) of the laser treated AgNP solutions stored for weeks 1, 3 and 6 were used for the analysis. The results shows that about $90 \%$ of the volume of the measured colloidal AgNP in the solution with no laser treatment contains particle sizes with a hydrodynamic diameter of approximately $37.84 \mathrm{~nm}$, in contrast with laser treated samples for 5 and $10 \mathrm{~min}$ were determined to be 10.1 and $8.72 \mathrm{~nm}$, respectively. The AgNP solutions exposed to Laser oblation at 5 and 10 min showed a shift to the left of PSD curve, thus indicative of the effect on size reduction. The laser treatment impacted the bigger particles; hence their molecular bonds were broken hence reducing the sizes. A slight change in size distribution was observed after $5 \mathrm{~min}$ of laser exposure, however, Takami et al. [31] reported to obtain an optimum effect at 5 10 min laser exposure. Figures $3(\mathrm{a})-(\mathrm{c})$ show no changes $(p>0.05)$ in PSD

Table 1. The means comparison by Duncan multiple range test of absorption, and concentration of AgNP nanosolutions exposed to laser oblations.

\begin{tabular}{ccc}
\hline Laser Ablation Time $(\mathrm{min})$ & Absorbance $(\mathrm{AU})$ & Concentrations $(\mathrm{PPM})$ \\
\hline 10 & $4.49^{\mathrm{a}}$ & $229.3^{\mathrm{a}}$ \\
5 & $4.39^{\mathrm{b}}$ & $224.3^{\mathrm{b}}$ \\
0 & $4.19^{\mathrm{c}}$ & $213.9^{\mathrm{c}}$ \\
\hline
\end{tabular}

Means with the letter in the same column are significantly different $(p<0.05)$. 
Kinetics of Reaction Control Treatment (T82)

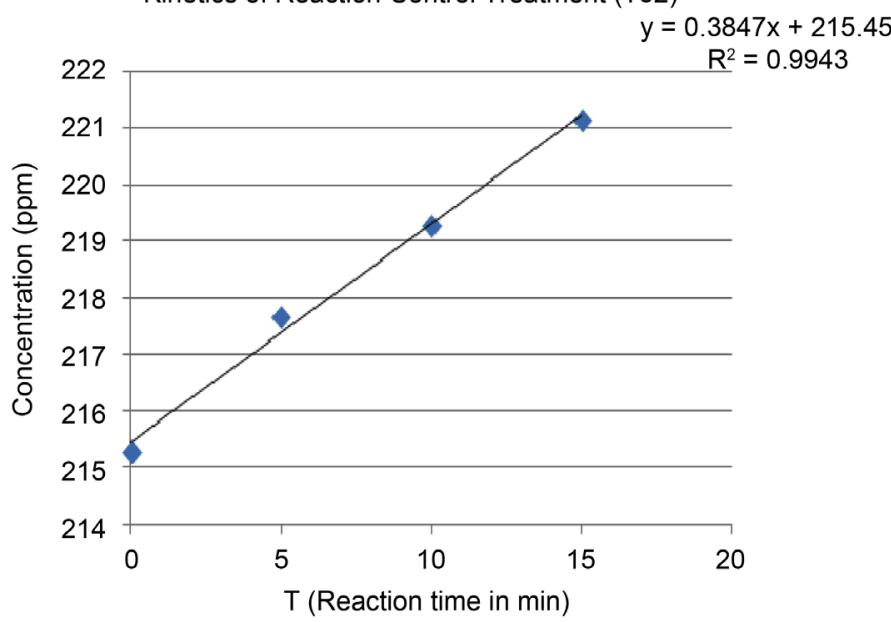

(a)

Kinetics of Reaction Laser Treatment 5 min (T83)

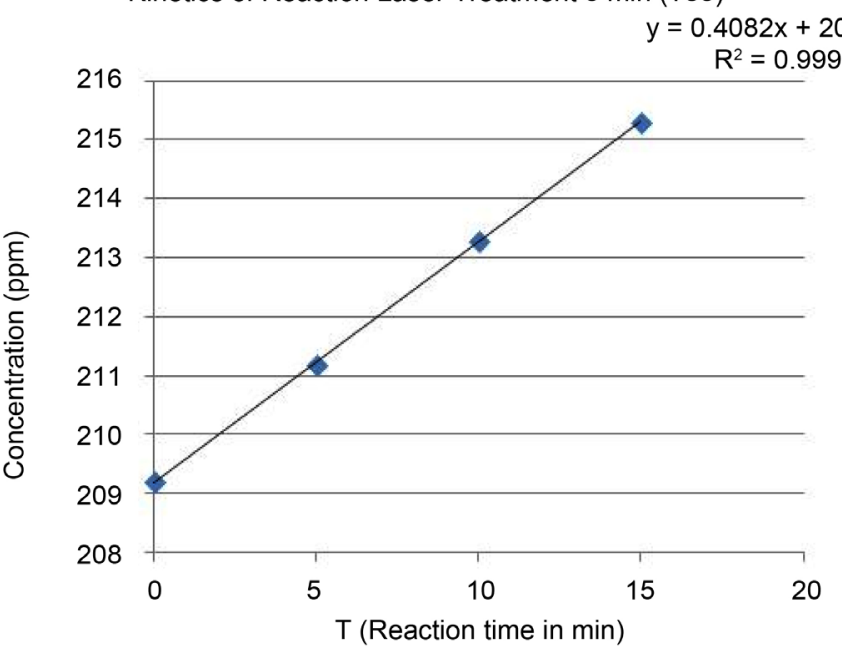

(b)

Kinetics of Reaction Laser Treatment 10 min (T84)

$y=0.4288 x+221.15$

$R^{2}=0.9995$

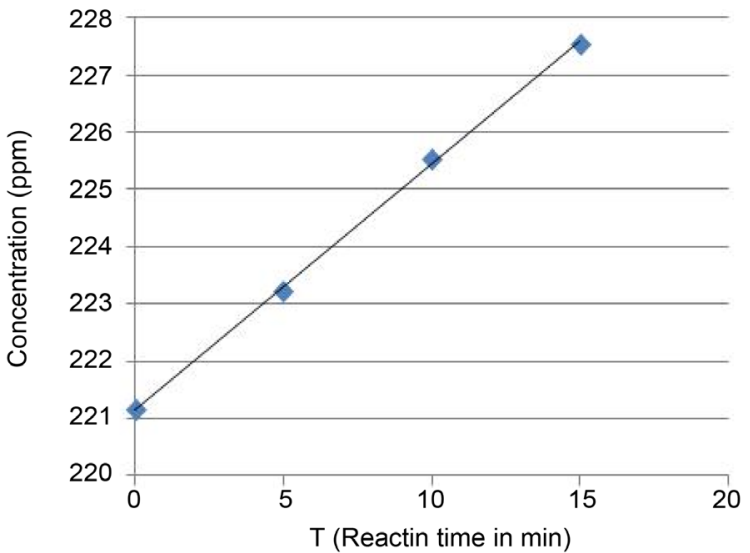

(c)

Figure 2. Reaction kinetics of laser oblation of AgNP at three different treatment times: (a) time $0 \mathrm{~min}$ (no treatment); (b) time 5 min; (c) time $10 \mathrm{~min}$. 
Size Distrbution by Volume

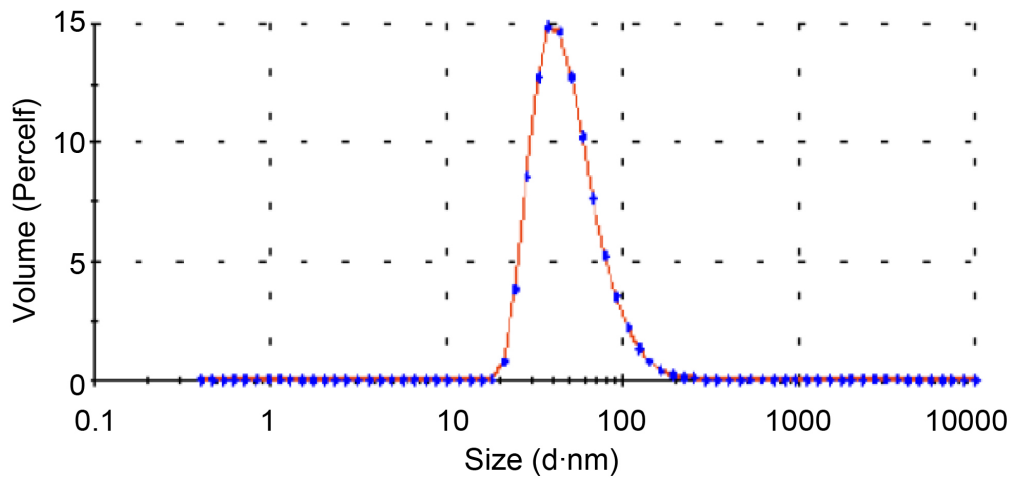

Record: 380 T82

(a)

Size Distrbution by Volume

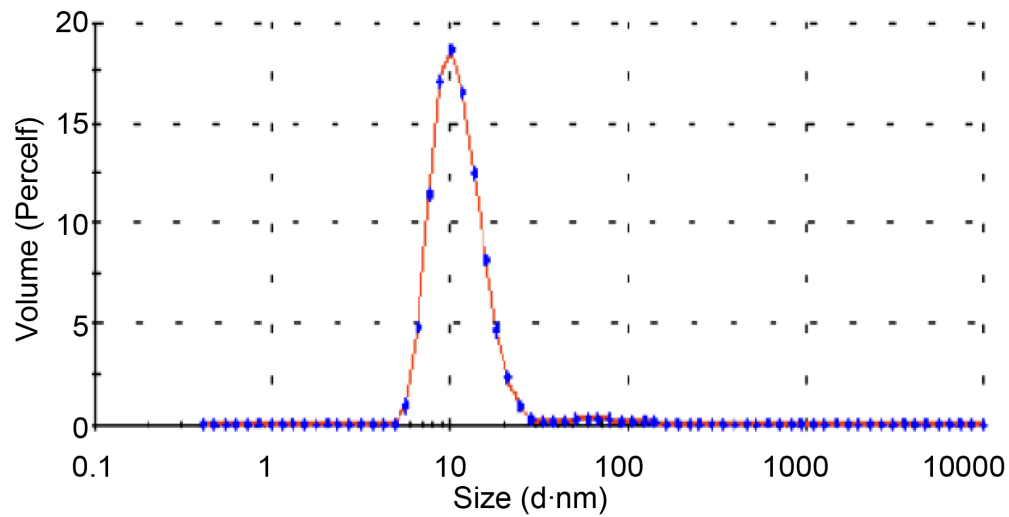

+Record 528: T83

(b)

Size Distrbution by Volume

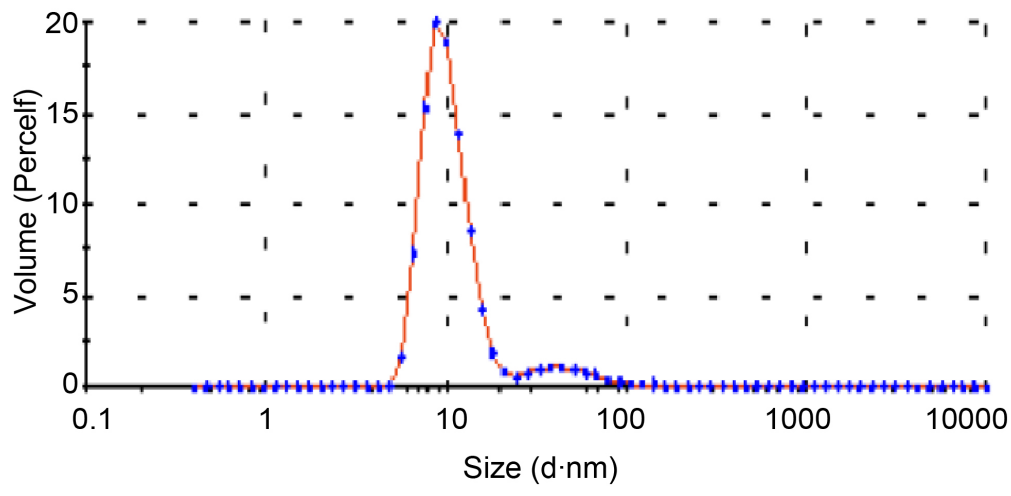

-Record 514: T84

(c)

Figure 3. (a) PSD measurements by volume for treatmentT82 with no laser at week six of storage. (b) PSD measurements by volume for treatmentT83 at laser exposure time of $5 \mathrm{~min}$ at week six of storage. (c) PSD measurements by volume for treatmentT84 at laser exposure of $10 \mathrm{~min}$ at week six of storage. 
after 6 weeks in storage, likewise no changes was also observed in week 1 (not shown). Therefore, fairly no significant $(p>0.05)$ flocculation of the dispersed particles occur during the storage period, hence an indication of electrokinetic particle stability.

\subsection{Zeta Potential Analysis}

The nanoparticles dispersed in solution are usually energetic under constant repulsion to the adjacent similarly charged particles in motion. The electrokinetic potential in the colloidal dispersion measured on this study ranges between \pm 40 $\mathrm{mV}$, as shown in Figures $4(\mathrm{a})-(\mathrm{c})$, hence no significant difference $(P>0.05)$ was found amongst the different treatment. The AgNP during the storages periods did not undergo agglomeration/aggregation, hence the zeta potential value measure is the true mean of colloidal stability for the emulsion.

\subsection{Fourier Transform Infrared Spectroscopy Determination of Functional Groups}

Fourier Transform Infrared (FTIR) spectroscopy measurements were carried out to determine the biomolecular profile of the three treatments as shown in Figure 5. The infrared (IR) bands were used to characterize IR spectrum peaks that are associated to different biological compounds. Biomolecules (Phytochemicals) such as aliphatic amines, carbonyl, alkenes $(=C-H)$, alkanes $(C-H)$, alcohol $(\mathrm{O}-\mathrm{H})$ and unsaturated esters $(\mathrm{C}-\mathrm{O})$ are biological compounds present in most plant leaves. Fourier Transform Infrared spectrum obtained from the Aloevera ethanol extract and the three treatments is shown in Figure 5 and the functional groups computed in Table 2.

The FTIR profile of the three treatments showed similar peaks when compared to the ethanol Aloe Vera extract, thus indicative of the treatments consisting of common biomolecules. Rajendram et al. [32] reported functional compounds in Aloe Vera skin were identified at the following wave number $\left(\mathrm{cm}^{-1}\right) 611.4 ; 717.5 ; 1051.1 ; 1398.3 ; 1623.9 ; 1730.0 ; 2912.3 ; 3155.3$ and 3398.3 using FTIR. Stretches of AgNP were found in the three treatments except the ethanol extract of Aloe Vera at around $300-350 \mathrm{~cm}^{-1}$ confirming the presence of AgNP. In their report, Tamasa and Suman [33] also confirmed the presence of pronounced AgNP at a lower peak range of $500-550 \mathrm{~cm}^{-1}$, although, the leaf extract of Azadirachtaindica was used to synthesize the AgNP, yet, both bands were similar.

In the solution the AgNP were surrounded by proteins and metabolites constituents of the Aloe vera extract, hence the FTIR analysis confirmed that the carbonyl groups from the amino acid residues and proteins have stronger ability to bind metals. The proteins may have served as a capping agent for AgNP formation and a recipe for stability. This also suggests that the biological molecules could possibly perform dual functions and thus could contribute to the formation and stabilization of silver nanoparticles in the aqueous medium [33]. The 


\section{Zeta Potential Distribution}

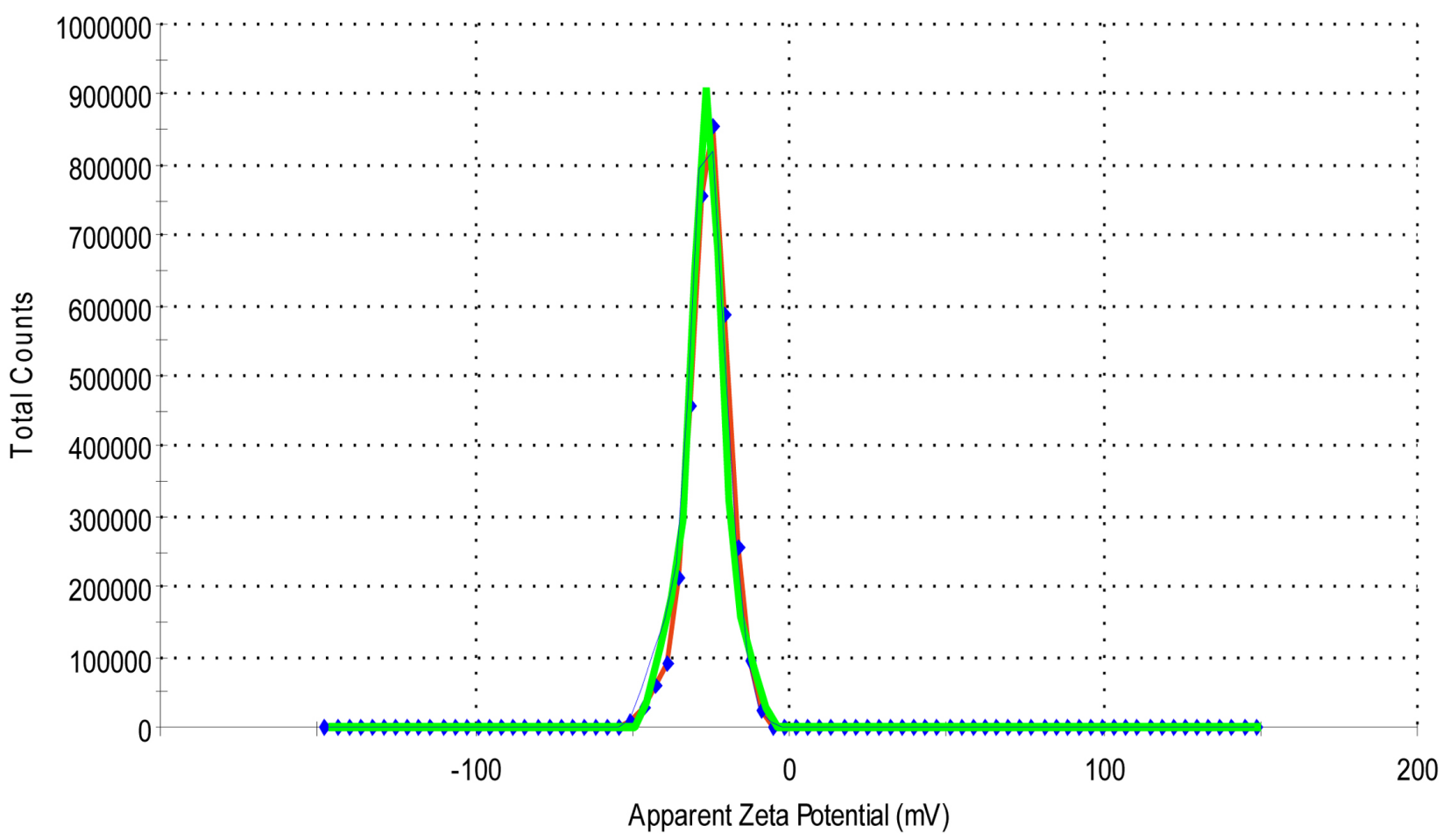

$\longrightarrow$ Record 412: T $821 \div$ Record 413: T $822 \div$ Record 414: T 82 3

(a)

Zeta Potential Distribution

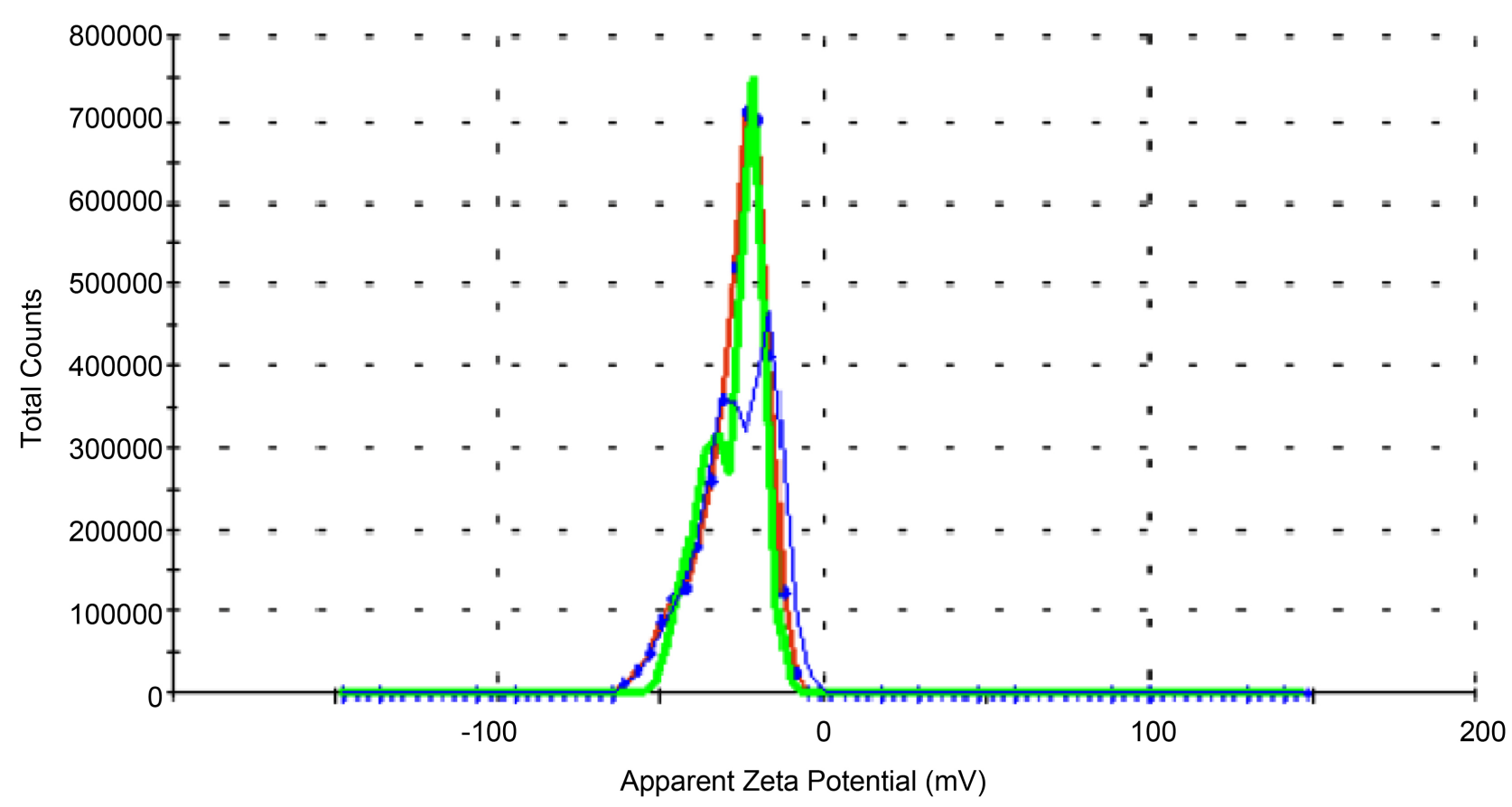

Record 490: T $831 \quad$ Record: 491: T $832 \quad$ - Record 492: T 833

(b) 


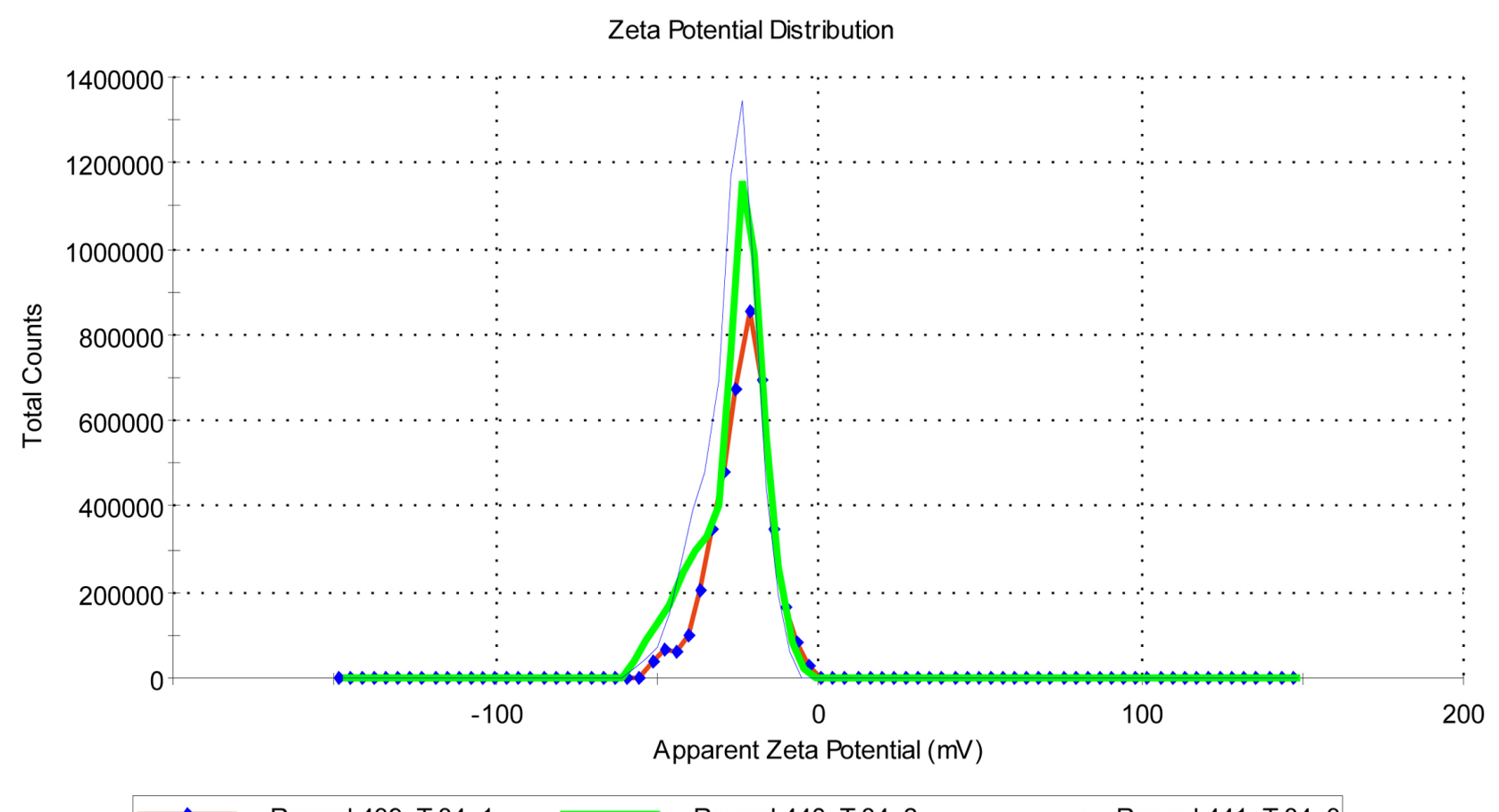

Record 440: T84 2

Record 441: T 843

(c)

Figure 4. (a) Zeta potential profile of the control T82 with no laser at week six of storage. (b) Zeta potential profile for treatmentT83 at laser exposure time of $5 \mathrm{~min}$ at week six of storage. (c) Zeta potential profile for treatmentT84 at laser exposure time of $10 \mathrm{~min}$ at week six of storage.

presence of the Carbonyl groups is an indication that flavonoids or terpenoids are absorbed on the surface of AgNP. These issues can be identified once the various fractions of the Aloe veraleaf extract are separated and to individually assayed their reduction potentials of metal ions.

Although the intensity of the functional groups of laser oblation treatments at 5 and 10 min diminishes with laser exposure times, yet the functional groups are present at higher concentration.

It can be concluded based on the results obtained of the effect of laser oblation that the particle starts to evaporate from the surface as soon as its temperature approaches the boiling point during the treatment. Continual evaporation of the particles at the boiling temperature contributes to the decreases in the particle sizes [34]. Therefore, the particle concentration increases dramatically due to the bonds broken by laser treatment and releases more concentrated organic compounds as the bigger particles disappear [31].

The result obtained from the ANOVA shows laser exposure significantly $(p<$ 0.01 ) impacted the concentration of the chemical substituent of the produced AgNP. Hence, the Duncan mean comparison for the different laser exposure times shown in Table 3, which shows the effect of laser oblation treatments on the chemical constituents and concentrations of the treatments. The concentrations increased significantly $(p<0.05)$ with laser exposure times. The amines, esters, alkynes, and carboxylic acids concentration are higher when the $10 \mathrm{~min}$ 


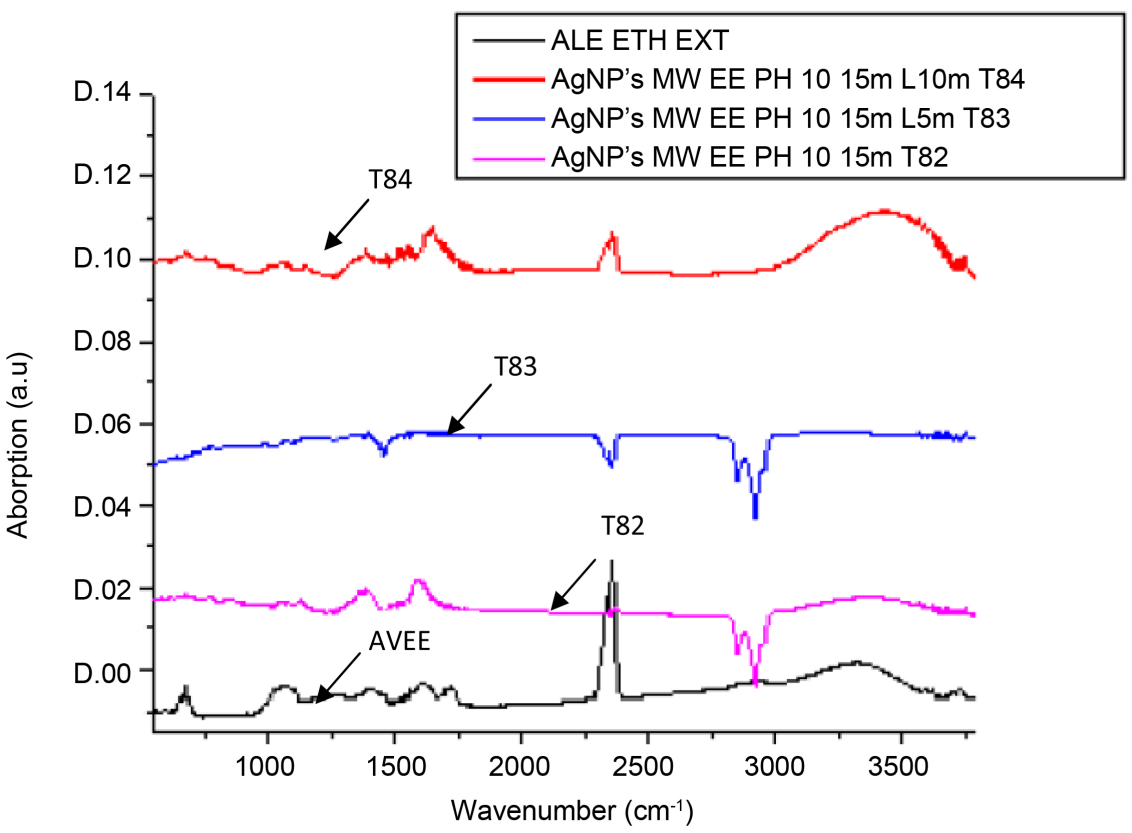

Figure 5. FTIR spectra of (1) Aloe Veraethanol extracts (AVEE), (2) the control, AgNP produced by microwave assisted method with no laser (T82), (3) AgNP produced by microwave assisted method with laser treatment of 5 min (T83), (4) AgNP produced by microwave assisted method with laser treatment of $10 \mathrm{~min}(\mathrm{~T} 84)$.

Table 2. Infrared absorption bands and functional groups of the three laser oblation treatments.

\begin{tabular}{ccccc}
\hline Wave Number & Functional Groups & $\begin{array}{c}\text { Laser } \\
\text { Treatment } \\
(0 \mathrm{~min})\end{array}$ & $\begin{array}{c}\text { Laser } \\
\text { Treatment } \\
(5 \mathrm{~min})\end{array}$ & $\begin{array}{c}\text { Laser } \\
\text { Treatment } \\
(10 \mathrm{~min})\end{array}$ \\
\hline 535.5 & CEC-H:C-H (alkynes)??? & Present & Present & Present \\
1005.9 & C-O stretch (aliphatic esters) & Present & Present & Present \\
1158.5 & C-N stretch (aliphatic amines) & Present & Present & Present \\
1247 & C-N stretch (aliphatic amines) & Present & Present & Present \\
1323.7 & N-O symmetric stretch (nitroalkane) & Present & Present & Present \\
1412.3 & O-H bend (carboxylic acid) & Present & Present & Present \\
1603.6 & N-H (amines) & Present & Present & Present \\
1743.5 & C-O stretch (aliphatic esters) & Present & Present & Present \\
2162.5 & -C $\Xi$ C-stretch (alkynes) & Present & Present & Present \\
2353 & C-N??? & Present & Present & Present \\
2862.1 & C-H stretch (alkanes) & Present & Present & Present \\
2925.4 & C-H stretch (alkanes) & Present & Present & Present \\
3357.8 & N-H (amines) & Present & Present & Present \\
\hline
\end{tabular}

laser treatment is applied in contrast to when no treatment. Therefore, we can surmise that laser oblation typically influences chemical substituent of AgNP. 
Table 3. Duncan mean comparison combined table of Chemical substituent of the three treatments at phase 2 of the experiment at different concentrations.

\begin{tabular}{cccccccc}
\hline $\begin{array}{c}\text { Laser } \\
\text { Ablation } \\
\text { Time }\end{array}$ & $\begin{array}{c}\text { Aliphatic } \\
\text { Amines }\end{array}$ & $\begin{array}{c}\text { Aliphatic } \\
\text { Esters }\end{array}$ & Amines & Alkynes & Amines & $\begin{array}{c}\text { Carboxylic } \\
\text { Acids }\end{array}$ & Nitroalkanes \\
\hline 10 & $7.68^{\mathrm{a}}$ & $7.95^{\mathrm{a}}$ & $8.07^{\mathrm{a}}$ & $6.13^{\mathrm{a}}$ & $7.22^{\mathrm{a}}$ & $6.37^{\mathrm{a}}$ & $7.22^{\mathrm{a}}$ \\
5 & $3.01^{\mathrm{b}}$ & $3.07^{\mathrm{b}}$ & $3.12^{\mathrm{b}}$ & $2.61^{\mathrm{b}}$ & $2.94^{\mathrm{b}}$ & $2.84^{\mathrm{b}}$ & $2.94^{\mathrm{b}}$ \\
0 & $1.24^{\mathrm{c}}$ & $1.32^{\mathrm{c}}$ & $1.42^{\mathrm{c}}$ & $0.90^{\mathrm{c}}$ & $0.76^{\mathrm{c}}$ & $0.79^{\mathrm{c}}$ & $0.76^{\mathrm{c}}$ \\
\hline
\end{tabular}

Means with the letter in the same column are significantly different $(p<0.05)$.

\section{Conclusion}

The results of the analysis show that laser oblation treatment has significant effect $(p<0.01)$ on the concentration of AgNP during synthesis. The intensity of the absorption peak significantly $(p<0.01)$ increases with laser exposure time. While $214 \mathrm{ppm}$ was observed for the control (no laser treatment), increased concentrations (224 and $229 \mathrm{ppm}$ ) were observed when laser treated for 5 and 10 min, respectively. The FTIR results show significant $(p<0.05)$ increase in biomolecules concentration of aliphatic amines, alkenes $(=C-H)$, alkanes $(C-H)$, alcohol $(\mathrm{O}-\mathrm{H})$ and unsaturatedesters $(\mathrm{C}-\mathrm{O})$, although the intensity of the functional groups diminishes with laser exposure times.

\section{Acknowledgements}

The authors' wishes to acknowledge the financial support of the USDA National Institute of Food and Agriculture, [USDA-NIFA Capacity Building Grant Project Title: Nanotechnology Application in the Food Engineering Curriculum. Accession number 230755]. Likewise the AAMU experimental station for committing resources in support of the research project.

\section{References}

[1] Mittal, A.K., Chisti, Y. and Banajee, U.C. (2013) Synthesis of Metallic Nanoparticles Using Plant Extracts. Biotechnology Advances, 31, 346-356. https://doi.org/10.1016/j.biotechadv.2013.01.003

[2] Mohanpuria, P., Rana, N.K. and Yadav, S.K. (2008) Biosynthesis of Nanoparticles: Technological Concepts and Future Applications. Journal of Nanoparticle Research, 7, 9275-9280. https://doi.org/10.1007/s11051-007-9275-x

[3] Rai, M., Yadav, A. and Gade, A. (2008) Current Trends in Phytosynthesis of Metal Nanoparticles. Critical Reviews in Biotechnology, 28, 277-284.

https://doi.org/10.1080/07388550802368903

[4] Sharma, V., Yngard, R. and Lin, Y. (2009) Silver Nanoparticles: Green Synthesis and Their Antimicrobial Activities. Advances in Colloid and Interface Science, 145, 83-96. https://doi.org/10.1016/j.cis.2008.09.002

[5] Bar, H., Bhui, D.K., Sahoo, G.P., Sarkar, P., De, S.P. and Misra, A. (2009a) Green Synthesis of Silver Nanoparticles Using Latex of Jatropha curcas. Colloids and Surfaces A: Physicochemical and Engineering Aspects, 339, 134-139. https://doi.org/10.1016/j.colsurfa.2009.02.008 
[6] Korbekandi, H. and Iravani, S. (2012b) Silver Nanoparticles. In: Hashim, A.A., Ed., The Delivery of Nanoparticles, InTech, ISBN: 978-953-51-0615-9. https://doi.org/10.5772/34157

[7] Kalishwaralal, K., Deepak, V., Ramkumarpandian, S., Nellaiah, H. and Sangiliyandi, G. (2008) Extracellular Biosynthesis of Silver Nanoparticles by the Culture Supernatant of Bacillus licheniformis. Materials Letters, 62, 4411-4413. https://doi.org/10.1016/j.matlet.2008.06.051

[8] Nair, B. and Pradeep, T. (2002) Coalescence of Nanoclusters and Formation of Submicron Crystallites Assisted by Lactobacillus Strains. Crystal Growth \& Design, 2, 293-298. https://doi.org/10.1021/cg0255164

[9] McIntyre, T.C., McCutcheon, S.C. and Schnoor, J.L. (2003) Phytoremediation: Transformation and Control of Contaminants. John Wiley \& Sons, Hoboken, NJ, USA.

[10] Iravani, S. (2004) Green Synthesis of Metal Nanoparticles Using Plants. Green Chemistry, 13, 2638-2650. https://doi.org/10.1039/c1gc15386b

[11] Korbekandi, H., Iravani, S. and Abbasi, S. (2009) Production of Nanoparticles Using Organisms Production of Nanoparticles Using Organisms. Critical Reviews in Biotechnology, 29, 279-306. https://doi.org/10.3109/07388550903062462

[12] Ankamwar, B., Damle, C., Ahmad, A. and Sastry, M. (2005) Biosynthesis of Gold and Silver Nanoparticles Using Emblica officinalis Fruit Extract, Their Phase Transfer and Transmetallation in an Organic Solution. Journal of Nanoscience and Nanotechnology, 1665-1671. https://doi.org/10.1166/jnn.2005.184

[13] Kassama, L., Kuponiyi, A. and Kukhtareva, T. (2015a) Rapid Laser-Assisted Nanosizing Noble Silver Nanoparticles in Plant Extracts and Physiochemical Characterization. Journal of Contemporary Research, 5, 8-18.

[14] Kuponiyi, A., Kassama, L. and Kukhtareva, T. (2014) Physicochemical Characterization of Silver Nanoparticles Synthesize Using Aloe Vera (Aloe barbadensis). Nanobiosystems: Processing, Characterization, and Applications, 7, 1-12.

[15] Okafor, F., Janen, A., Kukhtareva, T., Edwards, V. and Curley, M. (2013) Green Synthesis of Silver Nanoparticles, Their Characterization, Application and Antibacterial Activity. International Journal of Environmental Research and Public Health, 10, 5221-5238.

[16] Kasthuri, J., Kathiravan, K. and Rajendiran, N. (2008) Phyllanthin-Assisted Biosynthesis of Silver and Gold Nanoparticles: A Novel Biological Approach. Journal of Nanoparticle Research, 11, 1075-1085.

[17] Tripoli (2007) Citrus Flavonoids: Molecular Structure, Biological Activity and Nutritional Properties: A Review. Food Chemistry, 104, 466-479.

[18] Kavanagh, F. (1972) Analytical Microbiology. Academic Press, New York.

[19] Zhang, L., Jiang, Y., Ding, Y., Povey, M. and York, D. (2007) Investigation into the Antibacterial Behavior of Suspensions of $\mathrm{ZnO}$ Nanoparticles ( $\mathrm{ZnO}$ Nanofluids). Journal of Nanoparticle Research, 9, 479-489. https://doi.org/10.1007/s11051-006-9150-1

[20] Patel, K., Kapoor, S., Dave, D. and Mukherjee, T. (2006) Synthesis of Au, Au/Ag, $\mathrm{Au} / \mathrm{Pt}$ and $\mathrm{Au} / \mathrm{Pd}$ Nanoparticles Using the Microwave-Polyol Method. Research on Chemical Intermediates, 32, 103-113. https://doi.org/10.1163/156856706775372771

[21] Amendola, V. and Meneghetti, M. (2009) Laser Ablation Synthesis in Solution and Size Manipulation of Noblemetal Nanoparticles. Physical Chemistry Chemical Physics, 11, 3805-3821. https://doi.org/10.1039/b900654k 
[22] Bauer, C., Abid, J.P., Ferman, D. and Giault, H.H. (2004) Ultrafast Chemical Interface Scattering as an Additional Decay Channel for Nascent Nonthermal Electrons in Small Metal Nanoparticles. The Journal of Chemical Physics, 120, 9302-9315. https://doi.org/10.1063/1.1710856

[23] Correa, S.N., Naranjo, A.M. and Herrera, A.P. (2016) Biosynthesis and Characterization of Gold Nanoparticles Using Extracts of Tamarindusindica L Leaves. Journal of Physics: Conference Series, 687, 1-4. https://doi.org/10.1088/1742-6596/687/1/012082

[24] Shankar, S., Ahmad, A. and Sastry, M. (2003) Geranium Leaf Assisted Biosynthesis of Silver Nanoparticles. Biotechnology Progress, 19, 1627-1631. https://doi.org/10.1021/bp034070w

[25] Chandran, S.P., Chaudhary, M., Pasricha, R., Ahmad, A. and Sastry, M. (2006) Synthesis of Gold Nanotriangles and Silver Nanoparticles Using Aloe veraplant Extract. Biotechnology Progress, 22, 577-583. https://doi.org/10.1021/bp0501423

[26] Werner, D. and Hashimoto, S. (2013) Controlling the Pulsed-Laser-Induced Size Reduction of $\mathrm{Au}$ and Ag Nanoparticles via Changes in the External Pressure, Laser Intensity, and Excitation Wavelength. Langmuir, 29, 1295-1302. https://doi.org/10.1021/la3046143

[27] Bae, C.H., Nam, S.H. and Park, S.M. (2002) Formation of Silver Nanoparticles by Laser Oblation of s Silver Target in $\mathrm{NaCl}$ Solutions. Applied Surface Science, 197-198, 628-634.

[28] Kassama, L., Kuponiyi, A. and Kukhtareva, T. (2015b) Comparative Effects of Aloe Vera (Aloe barbadensis) extracts on the Physicochemical Properties and Stability of Silver Nanoparticles. Journal of Contemporary Research, 5, 30-39.

[29] Amal, A.E, Ayobami, J. and Ebtessam, E. (2012) In Situ Controlled Crystallization as a Tool to Improve the Dissolution of Glibenclamide. International Journal of Pharmaceutics, 428, 118-120.

[30] Nair, P. and Pander, T. (2012) Kinetics of Biosynthesis of Silver Nanoparticles Using Fusarium oxysporum. Current Trends in Technology \& Sciences, 1, 47-52.

[31] Takami, A., Kurita, H. and Koda, S. (1999) Laser Induced Size Reduction of Noble Metal Particles. The Journal of Physical Chemistry B, 103, 1226. https://doi.org/10.1021/jp983503o

[32] Rajendran, J.M. (2010) Isolation of Volatile Compounds of Aloe excelsa (Berger). African Journal of Biotechnology, 9, 7289-7294.

[33] Tamasa, P. and Suman, J. (2013) Synthesis and Characterization of Silver Nanoparticles Using Leaf Extract of Azadirachtaindica. Life Science National Institute of Technology, Rourkela.

[34] Pyatenko, A., Wang, H., Koshizaki, N. and Tsuji, T. (2013) Mechanism of Pulse Laser Interaction with Colloidal Nanoparticles. Laser \& Photonics Reviews, 7, 596-604. https://doi.org/10.1002/lpor.201300013 